\title{
Nicotine Decreases Bradykinesia-rigidity in Haloperidol-treated Patients with Schizophrenia
}

Yen Kuang Yang, M.D., Leann Nelson, M.D., Lakshmi Kamaraju, M.D., William Wilson, Ph.D., and Joseph P. McEvoy, M.D.

We applied nicotine $21 \mathrm{mg}$ and matching placebo transdermal patches to thirty haloperidol-treated patients with schizophrenia who smoked. Clinical assessments of bradykinesia-rigidity were lower during nicotine patch administration than during placebo patch administration.

[Neuropsychopharmacology 27:684-686, 2002]

(C) 2002 American College of Neuropsychopharmacology.

Published by Elsevier Science Inc.
KEY WORDS: Nicotine; Bradykinesia; Rigidity; Tremor; Haloperidol; Schizophrenia

Smoking is highly prevalent (60-80\%) among patients with schizophrenia, even at first episode before pharmacotherapy or institutionalization, and abnormalities of neuronal nicotinic acetylcholine receptors have been demonstrated in the brains of some patients with schizophrenia (Breese et al. 2000). Previous studies contrasting smokers with schizophrenia versus nonsmokers with schizophrenia have reported lower levels of bradykinesiarigidity but higher levels of tardive dyskinesia among the smokers (Goff et al. 1992). These studies are confounded by the enzyme-inducing effects of excipients in tobacco smoke that increase the metabolism and decrease the blood levels of most antipsychotics in smokers.

We report here the effects of nicotine (delivered by transdermal patch) versus placebo, on psychopathol-

From the National Cheng Kung University (Taiwan) (YKY), John Umstead Hospital, Butner, NC (LN, LK), and Duke University Medical Center, Durham, NC (WW, JPM).

Address correspondence to: Joseph P. McEvoy, M.D., John Umstead Hospital, $100312^{\text {th }}$ Street, Butner, NC 27509. Tel.: (919) 575-7190; Fax: (919) 575-7042; E-mail: jpmcevoy@duke.edu

Received August 3, 2001; revised February 19, 2002; accepted February 27, 2002.

Online publication: 3/4/02 at www.acnp.org/citations/ Npp030402257. ogy and extrapyramidal function, in 30 patients with schizophrenia, all of whom smoke.

\section{METHODS}

\section{Patient Population}

Thirty patients who met DSM-IV criteria for schizophrenia, and who smoked, provided signed informed consent to participate after the study was fully explained to them. Their mean (SD) age was 36 (10) years (range: 20 to 53 years). They had had 5 (5) prior hospitalizations (range: 0 to 16), and it had been 10 (9) years since their first hospitalizations (range; 0 to 26 years). Seven were women and twenty-three were men. All were inpatients recovering from an acute psychotic exacerbation, and all were treated with fixed neuroleptic threshold doses (McEvoy et al. 1991) of haloperidol during the study $(4.1 \pm 2.2 \mathrm{mg}$ /day; range 2 to $8 \mathrm{mg} /$ day).

\section{Smoking/Nicotine Procedures}

Smoking is permitted on our inpatient ward at the rate of one cigarette per hour, offered on the hour between 7 A.M. and 10 P.M. inclusive.

The study consisted of two assessment sessions, separated by a minimum of $24 \mathrm{~h}$. On each of the two as- 
sessment days, patients smoked their 7 A.M. cigarette. Immediately thereafter, a transdermal patch (Nicoderm $21 \mathrm{mg}^{\circledR}$ or matching placebo, in random sequence, double-blind) was applied. Patients then abstained from smoking until clinical assessments of psychopathology and extrapyramidal function were completed 2.5-3.0 $\mathrm{h}$ later, at which time serum nicotine levels were drawn and patches removed.

\section{Clinical Assessments}

All assessments were completed on all occasions by at least two of the three research psychiatrists (LK, JM, LN), and the average scores across the psychiatrists were used for all analyses.

The total score on a 16-item version of the Brief Psychiatric Rating Scale (BPRS) with item and anchor point descriptors was the psychopathology measure. The sums of three Bradykinesia-Rigidity items (Reported B-R, Observed B-R, Gait and Posture), two Tremor items (Reported, Observed), and two restlessness items (Reported, Observed) from the Extrapyramidal Side Effect Scale (McEvoy et al. 1991; McEvoy 2000), were used as the extrapyramidal function measures. In a larger sample of 63 patients (that included all the presently reported patients) examined together by all three research psychiatrists, but scored separately, unbiased estimates of inter-rater reliability for the BPRS total score (.92), the sum of the Bradykinesia-Rigidity items (.86), the sum of the Tremor items (.92), and the sum of the Restlessness items (.91) were all high.

\section{Statistical Procedures}

BPRS total scores were contrasted across the nicotine and placebo condition by means of two-tailed paired $t$-tests. Because the scores on the Bradykinesia-Rigidity, Tremor, and Restlessness sums did not appear to be normally distributed, these scores were contrasted across the nicotine and placebo conditions by means of non-parametric Wilcoxin Signed Ranks Tests. Order of patch application was examined in all analyses.

\section{RESULTS}

We examined whether the method we utilized (brief transdermal patch application) was effective in producing the experimental conditions we desired (substantial differences in serum nicotine levels across the two patch applications). Although mean (SD) serum nicotine levels differed significantly for the entire group of 30 patients $(4.9 \pm 4.3 \mathrm{ng} / \mathrm{ml}$ vs $16.1 \pm 6.4 \mathrm{ng} / \mathrm{ml} ; \mathrm{t}=$ $10.3, p<.001)$, six of these individual patients showed little difference in serum nicotine levels across patch applications, perhaps reflecting incorrect application or temporary removal of the patches by these psychotic patients. We repeated our analyses, first including only those $(\mathrm{n}=24)$ patients with $>1$ SD difference in plasma nicotine levels across the patch applications, and again including only those $(n=18)$ patients with $>2$ SD difference.

There was a trend for Bradykinesia-Rigidity to be reduced during the nicotine patch administration across all patients (Table 1); this advantage became statistically significant when only patients with $>1$ SD difference in nicotine serum levels were included, and strengthened further when only patients with $>2$ SD difference in nicotine serum levels were included. There was a trend for Tremor to be reduced during the nicotine patch administration when only patients with $>1 \mathrm{SD}$ difference in nicotine serum levels were included, and this advantage became statistically significant when only patients with $>2$ SD difference in nicotine serum levels were included.

There was no evidence for a nicotine effect on the BPRS total score, or on Restlessness. It should be noted

Table 1. Effects of Nicotine $21 \mathrm{mg}$ versus Placebo Transdermal Patch on Clinical Measures of Extrapyramidal Function

\begin{tabular}{|c|c|c|c|}
\hline & $\begin{array}{l}\text { All patients } \\
\quad(n=30)\end{array}$ & $\begin{array}{c}\text { Patients with }>1 \text { SD } \\
\text { difference in } \\
\text { nicotine levels }(n=24)\end{array}$ & $\begin{array}{c}\text { Patients with }>2 \text { SD } \\
\text { difference in } \\
\text { nicotine levels }(n=18)\end{array}$ \\
\hline \multicolumn{4}{|c|}{ Bradykinesia-Rigidity } \\
\hline Nic 21 & $1.9(1.4)$ & $1.7(1.2)$ & $1.3(1.0)$ \\
\hline \multirow[t]{2}{*}{ PBO } & $2.4(1.4)$ & $2.3(1.3)$ & $2.2(1.3)$ \\
\hline & $z=1.82, p=.069$ & $\mathrm{z}=2.04, p=.042$ & $\mathrm{z}=2.42, p=.016$ \\
\hline \multicolumn{4}{|l|}{ Tremor } \\
\hline Nic 21 & $0.9(1.0)$ & $1.0(1.0)$ & $0.9(1.1)$ \\
\hline \multirow[t]{2}{*}{ PBO } & $1.2(1.0)$ & $1.3(1.3)$ & $1.4(1.1)$ \\
\hline & $\mathrm{z} 1.58, p=.114$ & $\mathrm{z}=1.71, p=.087$ & $\mathrm{z}=2.18, p=.029$ \\
\hline
\end{tabular}


that scores on Restlessness were very low, perhaps reflecting the low haloperidol doses we used.

Order of patch application was not significant in any analysis.

\section{DISCUSSION}

Epidemiological studies suggest that smokers are significantly less likely than nonsmokers to develop Parkinson's Disease (Morens et al. 1995). In patients with Parkinson's Disease, nicotine may produce slight improvements in bradykinesia-rigidity (Fagerstrom et al. 1994). In normal individuals, patients with Parkinson's Disease, and patients with schizophrenia treated with conventional neuroleptics, nicotine improves reaction time and processing speed on cognitive psychomotor testing (Kelton et al. 2000; Levin et al. 1996). Our study suggests that, in patients with schizophrenia treated with haloperidol, nicotine can produce clinically detectable improvements in bradykinesia-rigidity, and, to a lesser extent, tremor. Dalack et al. (1999) reported no effect of nicotine on bradykinesia-rigidity or tremor. If nicotine causes dopamine release (Morens et al. 1995), this effect may only be reflected clinically if the levels of conventional antipsychotic are close enough to the neuroleptic threshold to be overwhelmed by the additional dopamine.

\section{REFERENCES}

Breese CR, Lee MJ, Adams CE, Sullivan B, Logel J, Gillen K, Marks MJ, Collins AC, Leonard S (2000): Abnormal regulation of high affinity nicotine receptors in subjects with schizophrenia. Neuropsychopharmacology 23:351-364

Dalack GW, Becks L, Hill E, Pomerleau OF, Meador-Woodruff JH (1999): Nicotine withdrawal and psychiatric symptoms in cigarette smokers with schizophrenia. Neuropsychopharmacology 21:195-202

Fagerstrom KD, Pomerleau O, Giordani B, Stelson F (1994): Nicotine may relieve symptoms of Parkinson's disease. Psychopharmacology (Berl) 116:117-119

Goff DC, Henderson DC, Amico E (1992): Cigarette smoking in schizophrenia: Relationship psychopathology and medication side effects. Am J Psychiatry 149:1189-1194

Kelton MC, Kahn HJ, Conrath CL, Newhouse PA (2000): The effects of nicotine on Parkinson's disease. Brain Cogn 43:274-282

Levin ED, Wilson W, Rose JE, McEvoy JP (1996): Nicotinehaloperidol interactions and cognitive performance in schizophrenia. Neuropsychopharmacology 15:429-436

McEvoy JP, Hogarty GE, Steingard S (1991): Optimal dose of neuroleptic in acute schizophrenia. Archives of General Psychiatry 48:739-745

McEvoy JP (2000): Guide to Assessment Scales in Schizophrenia. Science Press, London.

Morens DM, Grandinetti A, Reed D, White LR, Rose GW (1995): Cigarette smoking and protection from Parkinson's disease: False association or etiologic clue? Neurology 45:1041-1051 